\title{
The Role of Portoenterostomy with Aggressive Hilar Dissection in Biliary Tract Tumors: Report of Case Series and Review of the Literature
}

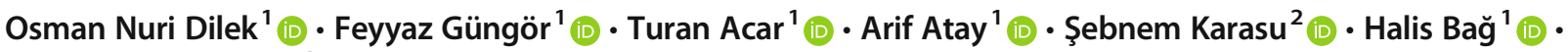 \\ Fatma Hüsniye Dilek $^{3}$ (D)
}

Received: 18 January 2020 / Accepted: 24 April 2020 / Published online: 12 May 2020

(C) Association of Surgeons of India 2020

\begin{abstract}
Hepaticojejunostomy is a challenging and complex procedure to be done with confidence in conditions that contain a large number of segmental bile ducts. Portoenterostomy can be defined as the joining of multiple bile ducts into a single cavity using segmenter bile duct ends, stents, and surrounding connective tissues. During surgery, in cases with advanced stage biliary tract tumors that cannot be performed hepatectomy, after aggressive dissections to provide a negative surgical margin, a large number of segmental bile ducts can be revealed and needs to ensure the continuity of bile flow. Here, our clinical series of portoenterostomy (PE) in which we applied in patients who had aggressive hilar dissection and resection for hilar cholangiocarcinomas and biliary tract tumors were discussed. The study included 15 patients who underwent PE for biliary tract tumors and hilar cholangiocarcinomas between 2015 and 2019. Six of the patients had a tumor-negative surgical margin, with a mean follow-up of 14.4 months (range 2 to 28 months). Nine of the patients had a tumorpositive surgical margin, with a mean follow-up of 7.7 months (range 2 to 17 months). Portoenterostomy instead of hepaticojejunostomy in small and multiple biliary radicles and bile duct cancers has been successfully performed in 15 patients of bile duct cancer and Klatskin tumor. In the presence of active inflammation, fibrosis, major bile duct trauma, and thin bile duct radicles, this method, which is described in detail, provides an excellent salvage surgical procedure with less morbidity.
\end{abstract}

Keywords Biliary tract tumor $\cdot$ Klatskin tumor $\cdot$ Portoenterostomy $\cdot$ Treatment

\section{Introduction}

Portoenterostomy $(\mathrm{PE})$ is the standard procedure for the treatment of biliary atresia $[1,2]$. However, there are very little literature data on its use and other indications [3-6]. It is a complicated and challenging procedure to maintain hepaticojejunostomy involving multiple segmental bile ducts damaged by tumors or benign pathologies. There are serious complications such as fistula, cholangitis, and stricture, as well

Osman Nuri Dilek

osmannuridilek@gmail.com

1 Department of Surgery, Atatürk Research and Education Hospital, İzmir Katip Celebi University, İzmir, Turkey

2 Department of Radiology, Atatürk Research and Education Hospital, İzmir Katip Celebi University, İzmir, Turkey

3 Department of Pathology, Atatürk Research and Education Hospital, İzmir Katip Celebi University, İzmir, Turkey as the technical difficulties during the treatment of cholangiocarcinomas involving biliary tract bifurcation $[5,7$, 8]. Endoscopic and interventional procedures to be applied in patients with biliary strictures adversely affect the comfort of life. Many patients are trying to survive with external and internal stents in this process. The prolongation of the process may lead to sepsis, hepatolithiasis, and cirrhosis [7]. Especially in bile duct tumors where hepatectomy cannot be performed, local or palliative resections are needed following aggressive dissections. A large number of segmental bile ducts may be encountered to provide a negative surgical margin.

Here, we aimed to present our results of portoenterostomy (PE) experience in cases where aggressive dissection and resection are needed in hilar areas due to hilar cholangiocarcinomas.

\section{Material and Methods}

The files of patients who underwent surgery for extrahepatic bile duct (EHBD) tumors and Klatskin tumors in the last 
4 years in our hospital were examined. Patients who underwent aggressive hilar resection and PE were included in the study.

The PE procedure was performed in the presence of 3 or more bile ducts that could not be merged (Fig. 1). The classic Roux-en-Y hepaticojejunostomy was performed to prevent postoperative ascending cholangitis [1,2,9]. The portal vein side initiated the anastomosis with interrupted sutures between the jejunum and the lateral wall of the bile duct (Fig. 2). In the gaps between the corner and channel stitches, the sutures passing through the hilar plate (liver tissue) and jejunum were used. The ropeway system was used when sewing.

All the posterior wall (vena porta side) sutures were first preplaced then tied. A $4 / 0$ polydioxanone was used as the suture material (PDS® II, Ethicon, Edinburgh, UK). A total of 6-8 stitches were laid on the back wall, and the sutures were tied on the outside. Care was taken to keep the jejunal mucosa inside. Thin-long silicone stents placed in the small diameter $(2 \mathrm{~mm})$ bile ducts coinciding with the anastomosis line were extended into the jejunum (Fig. 2). The longer part of the stents $(2 / 3$, approximately $8-10 \mathrm{~cm})$ was placed in the jejunum as unbound, which would subsequently fall under the influence of bowel peristalsis. Small bile ducts in the middle were released when the stitches of the anterior side of the anastomosis were started. A suture was passed through the outer walls of the small bile ducts, while the 2-3 stitches were crossed through the wide bile ducts that coincide with the corners of the anastomosis. More on the front, the remaining gaps between the corner sutures were closed with sutures passed through the liver parenchyma. After the end of the anastomosis, to decrease the tension, 2-3 approximation sutures were placed in the surrounding tissues. A Jackson-Pratt drain was placed in the operation area.

Patients who needed ventilator support postoperatively were followed up in the intensive care unit. Antibiotic, parenteral nutrition, and early enteral nutritional support were routinely used. No additional procedure was taken for the bile drainage that was seen and lost in the first week. Stents, which

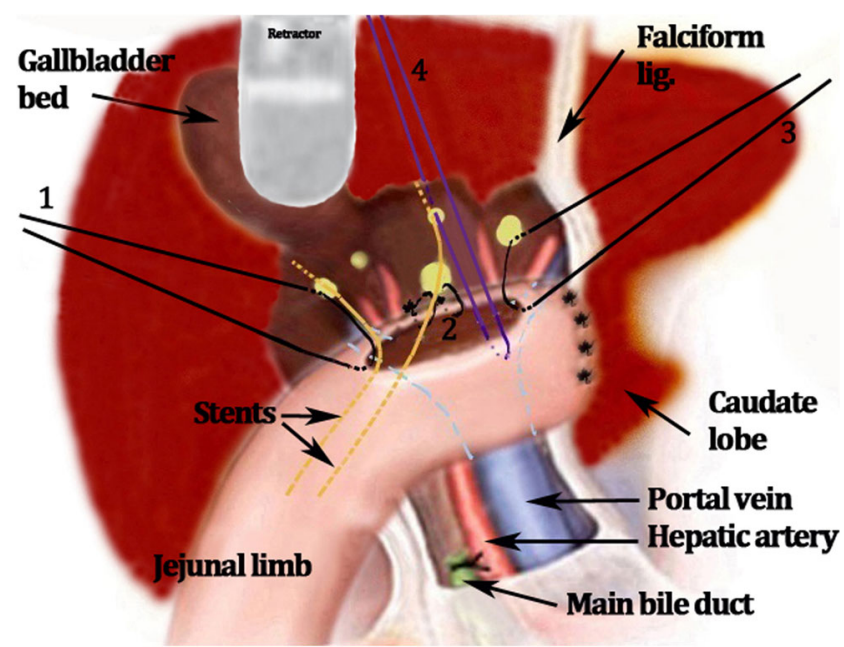

Fig. 2 The portoenterostomy stitch technique. Corner sutures $(1,3)$, posterior wall sutures (2), and anterior wall sutures between the jejunum and thin bile ducts (4)

were put into thin bile ducts, fell spontaneously. Anastomosis status and stents were checked with PTC or MRCP on the 10th-15th postoperative day (Fig. 3). In patients with PTC stent, the stents were removed first after control cholangiography, and the drains inside the abdomen were taken 1 day later. Postoperatively, the patients were examined at 36 months intervals and followed up by routine CT, MRI, and MRCP. In the patients who came to the control, bilirubin, alkaline phosphatase, liver enzymes, amylase, coagulation factors, tumor markers, CRP, leukocyte, and routine biochemical parameters were evaluated. USG, MRCP, and CT were performed for any progression, metastasis, or local recurrences.

As a routine procedure, written-signed informed consent form was obtained from all patients for treatment modalities and publication. İzmir Katip Celebi University, Atatürk Training, and Research Hospital, Human Research Ethics Committee approved study: 2019-GOKAE-1086.
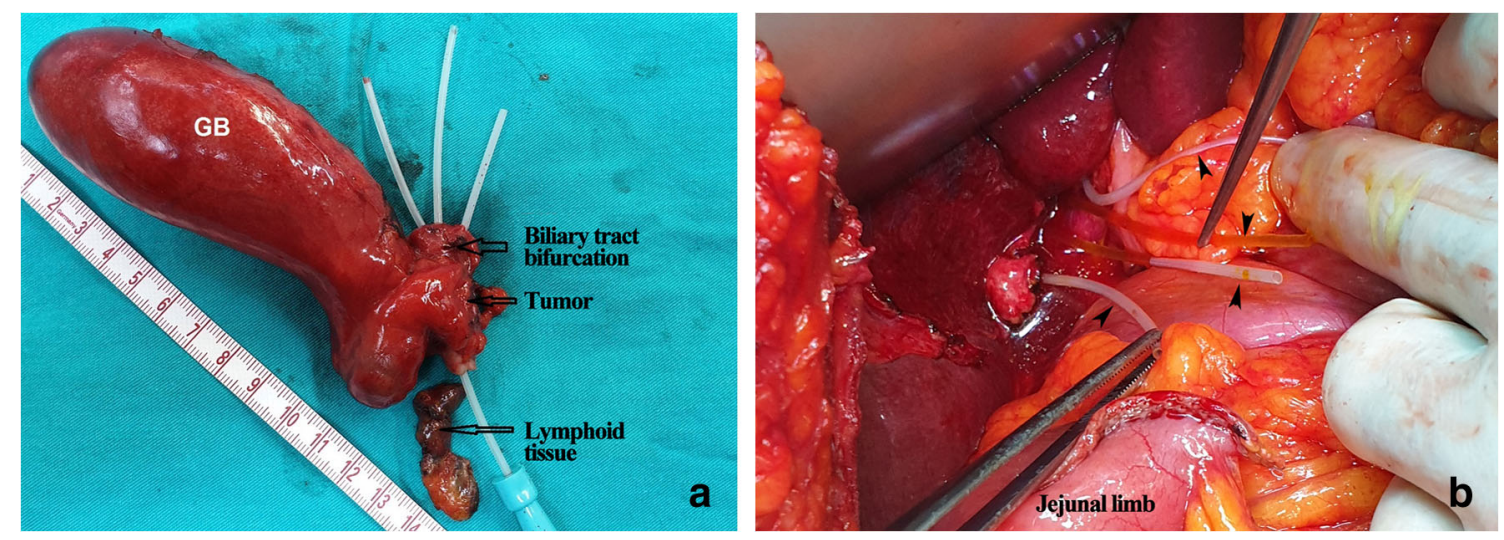

Fig. 1 a The specimen of hilar structures after aggressive hilar resection and multiple bile duct ends (stents). b Bile ducts (stents-arrow heads) 


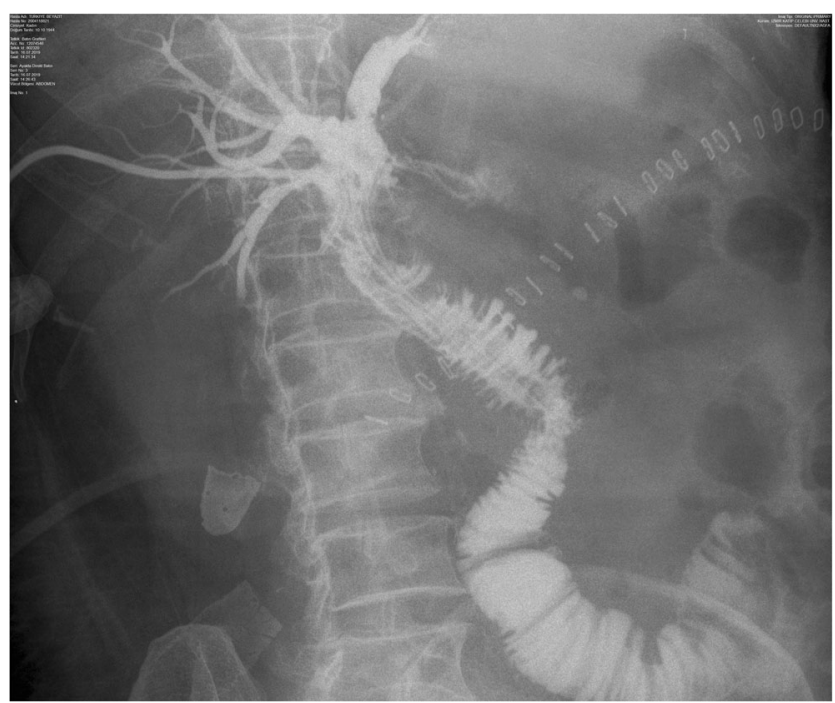

Fig. 3 Cholangiography taken postoperative 15 th day with the PTC catheter shows the anastomotic patency

\section{Results}

In the last 5 years, 36 out of 123 patients underwent surgery for EHBD tumors and Klatskin tumors. Extrahepatic biliary tract resection and/or hepatectomy and caudate lobe resection were performed in 21 of them. At the same time, 15 patients underwent portoenterostomy following aggressive hilar dissection.

Six of the 15 patients had a tumor-negative surgical margin, with a mean follow-up of 14.4 months (range 2 to 28 months). In one patient who underwent Whipple procedure due to EHBD tumor, hilar resection and PE were performed in the second session because histopathological examination revealed a tumor at the proximal surgical margin (Table 1). One patient who had been placed metal stent with ERCP for Klatskin tumor and then added PTC stent had been resected with aggressive hilar resection and then performed PE (Fig. 4). Four patients died during the follow-up period; one died from bleeding on the second postoperative day, the other died from pneumonia at 2 months, and two died from metastases at 11 and 28 months. The rest two patients of these groups were still under follow-up.

Nine of the 15 patients had a tumor-positive surgical margin, with a mean follow-up of 7.7 months (range 2 to 17 months) (Table 1). In one patient, portoenterostomy was performed by EHBD resection, hilar dissection, segment 4B and 5 resections, and Whipple procedure. In two patients, the Whipple procedure was also performed since the distal surgical margin was positive. Since hepatic duct invasion was also detected in two patients with gallbladder carcinoma, hepatic duct bifurcation was resected along with segments $4 \mathrm{~B}$ and 5 . Seven patients died during the follow-up period, one died from COPD and pneumonia, and two patients with gallbladder carcinoma died due to local recurrence and metastasis at 3 and 10 months. The four patients died due to metastases and recurrence. The rest two patients were still under follow-up (Table 1).

The mean follow-up period for all patients was 9.4 months (range 2 to 28 months). Totally four patients of our series were still under follow-up.

\section{Discussion}

Hepaticojejunostomy is sufficient in most cases where the main biliary tract is resected. However, it is challenging to perform hepaticojejunostomy in cases with multiple biliary tract resections, and portoenterostomy may be required. Portoenterostomy is the standard treatment for biliary atresia. Portoenterostomy can be defined as the joining of multiple bile ducts into a single cavity using segmenter bile duct ends, stents, and surrounding connective tissues. There is little clinical information in the literature regarding the use of PE for other pathologies except for major bile duct traumas. Recently, a few cases and case series that underwent portoenterostomy for different hilar pathologies have been reported [3, 4].

The incidence and mortality of hilar region tumors (Klatskin tumor), which constitute $50-70 \%$ of bile duct tumors, are increasing worldwide [10]. Resection with negative surgical margin (R0, cancer-free margin) is the gold standard in the treatment of biliary tract tumors. However, only 10 $20 \%$ of cases can be curative resection [11]. Mortality rates are reported to be $10-15 \%$, and morbidity rates are $20-66 \%$ in experienced centers after aggressive resection [12]. In the classical/standard approach, once hilar cholangiocarcinoma progressed in the right or left main hepatic canal (BismuthCorlette $3 \mathrm{~A}, 3 \mathrm{~B}, 4$ ), caudate lobe resection is added to the right or left lobe hepatectomy. [13]. In 20-50\% of patients who underwent laparotomy for curative resection, the cases are inoperable. Besides the biological properties of the tumor, it is known that the tumor size, extensive intraepithelial spread, perineural invasion, as well as the stents placed with PTC or ERCP have a role in the further spread of the tumor $[14,15]$. Matsuo et al. reported the series of 380 cases of hilar cholangiocarcinoma [16]. They explored 295 cases, resected in 157 of them, and had R0 surgical margins in 120 patients $(76.4 \%)$. R0 resection rate after surgical treatment has been reported as $35-78 \%$ in the literature $[7,16]$. Going back is not easy in some patients who undergo aggressive longitudinal dissection (along with the bile duct axis) in the segmental or higher level to provide surgical margin negativity. In cases where the negative surgical margin (R0) cannot be achieved, and the tumor continues as R1 or R2, removal of the dissected tissue and tumor may become necessary. Disruption of the bleeding of the dissected bile ducts, enlargement of the hepatectomy limit, increased risk of developing liver failure, and comorbidities may remain in the operation drainage or 
Table 1 Demographic data of the patients

\begin{tabular}{|c|c|c|c|c|c|}
\hline $\mathrm{Pt}$ & $\mathrm{M} / \mathrm{F}$ age & $\begin{array}{l}\text { History/diagnosis/pathology/ } \\
\text { etiology }\end{array}$ & PTC/ERCP/Labs & Procedure & Results/survey \\
\hline 1. & F 76 & $\begin{array}{l}\text { Klatskin tumor (type 3) } \\
\text { Adenocarcinoma-G3 }\end{array}$ & $\begin{array}{l}\text { Bil.:21.60, Ca-19.9:355 } \\
\text { PTC stenting }\end{array}$ & EHBDR + PE (2015) & $\begin{array}{l}\text { Relaparotomy on 2nd day } \\
\text { excitus (hemorrhagic } \\
\text { shock) }\end{array}$ \\
\hline 2. & M 59 & $\begin{array}{l}\text { COPD, meningitis sequelae, } \\
\text { Klatskin tumor? (type 3) bile } \\
\text { duct ulcer, fibrosis, } \\
\text { cholestasis, benign stricture, } \\
\text { IgG4+, SM- }\end{array}$ & $\begin{array}{l}\text { Bil.: 20.07,Ca-19.9:197 } \\
\text { ERCP/PTC stenting (2017) }\end{array}$ & EHBDR + PE (2017) & $\begin{array}{l}\text { Evisceration-primary suture } \\
\text { (COPD, pneumonia), } \\
\text { excitus, } \\
2 \mathrm{~m}\end{array}$ \\
\hline 3. & M 58 & $\begin{array}{l}\text { Klatskin tumor (type 2-3) } \\
\text { Adenocarcinoma - G1 SM- }\end{array}$ & $\begin{array}{l}\text { Bil.:20.48, Ca-19.9:37 } \\
\text { PTC stenting }\end{array}$ & WP + + EHBDR + PE (2017) + CT & $\begin{array}{l}\text { Stabile + liver metastasis + } \\
\text { abscess + PTC stenting } \\
\text { excitus, } 28 \mathrm{~m}\end{array}$ \\
\hline 4. & M 69 & $\begin{array}{l}\text { Klatskin tumor (type 2) } \\
\text { Adenocarcinoma - G1 (neuro- } \\
\text { endocrine tumor), } \\
\text { SM- }\end{array}$ & $\begin{array}{l}\text { Bil.:15.99, Ca-19.9:Normal } \\
\text { ERCP stenting }\end{array}$ & $\mathrm{EHBDR}+\mathrm{PE}(2017)+\mathrm{CT}+\mathrm{RT}$ & $\begin{array}{l}\text { Liver metastasis } \\
\text { (recurrence?), excitus, } \\
11 \mathrm{~m}\end{array}$ \\
\hline 5. & F 76 & $\begin{array}{l}\text { Crohn's disease (2012), } \\
\text { Klatskin tumor } \\
\text { (type 3) } \\
\text { Adenocarcinoma - G2, SM- }\end{array}$ & $\begin{array}{l}\text { Bil.: } 24.35, \mathrm{Ca}-19-9: 112 \\
\text { PTC right and left stenting }\end{array}$ & EHBDR + PE (2018) + RT & Stabile, $19 \mathrm{~m}$ \\
\hline 6. & M 74 & $\begin{array}{l}\text { Klatskin tumor (type 3) } \\
\text { Adenocarcinoma - G3, SM- }\end{array}$ & $\begin{array}{l}\text { Bil.: 6.17,Ca-19.9:39 } \\
\text { ERCP stenting (2019) }\end{array}$ & $\mathrm{EHBDR}+\mathrm{PE}(2019)+\mathrm{CT}+\mathrm{RT}$ & $\begin{array}{l}\text { Bile leakage ( } 7 \text { days), liver } \\
\text { abscess (drainage), stabile, } \\
12 \mathrm{~m}\end{array}$ \\
\hline 7. & M 43 & $\begin{array}{l}\text { Klatskin tumor (type 3) } \\
\text { Invasion of portal vein conf., } \\
\text { Adenocarcinoma - G2, SM+ }\end{array}$ & $\begin{array}{l}\text { Bil.:17.44,Ca-19.9:129 } \\
\text { PTC stenting }\end{array}$ & $\mathrm{EHBDR}+\mathrm{PE}(2015)+\mathrm{RT}$ & $\begin{array}{l}\text { Liver metastasis, recurrence? } \\
\quad \text { excitus, } 17 \mathrm{~m}\end{array}$ \\
\hline 8. & M 66 & $\begin{array}{l}\text { Klatskin tumor (type 2) } \\
\text { Adenocarcinoma - G2, SM+ }\end{array}$ & $\begin{array}{l}\text { Bil.:24.11,Ca-19.9:93 } \\
\text { ERCP stenting }\end{array}$ & EHBDR+ PE (2016) & Excitus (etiology?) $9 \mathrm{~m}$ \\
\hline 9. & F 78 & $\begin{array}{l}\text { COPD + Klatskin tumor (type 3) } \\
\text { Adenocarcinoma - G1, SM+ }\end{array}$ & $\begin{array}{l}\text { Bil.:12.46,Ca-19.9:N } \\
\text { PTC stenting }\end{array}$ & EHBDR + PE (2017) & Pneumonia, excitus, 2 m \\
\hline 10. & F 61 & $\begin{array}{l}\text { Gallbladder carcinoma + EHBD } \\
\text { invasion } \\
\text { Adenocarcinoma - G3, SM+ }\end{array}$ & $\begin{array}{l}\text { Bil.:16.26, Ca-19.9:200 } \\
\text { PTC stenting }\end{array}$ & $\begin{array}{l}\text { Liver S4B and } 5 \text { resection } \\
\quad+\text { EHBDR + PE }(2018)+\text { RT }\end{array}$ & $\begin{array}{l}\text { Stabile, malign hypercalcemia } \\
\quad+\text { liver metastasis Excitus, } \\
10 \mathrm{~m}\end{array}$ \\
\hline 11. & M 68 & $\begin{array}{l}\text { Klatskin tumor (type 2) } \\
\text { Tumor thrombus } \\
\text { Adenocarcinoma-G3, SM+ }\end{array}$ & $\begin{array}{l}\text { Bil.:25+, Ca-19-9:52 } \\
\text { PTC, metal stent (ingrowth) } \\
\text { (2018), and 2nd stenting }\end{array}$ & $\begin{array}{l}\mathrm{EHBDR}+\mathrm{PE}(2019) \text { (refused CT } \\
\text { and RT) }\end{array}$ & $\begin{array}{l}\text { Recurrence and metastasis } \\
\text { excitus, } 5 \mathrm{~m}\end{array}$ \\
\hline 12. & M 74 & $\begin{array}{l}\text { Klatskin tumor, (type 3) } \\
\text { Adenocarcinoma - G3, SM+ }\end{array}$ & $\begin{array}{l}\text { Bil: } 11.9, \mathrm{Ca}-19.9: 41 \\
\text { ERCP + stenting }\end{array}$ & $\mathrm{EHBDR}+\mathrm{PE}(2019)+\mathrm{CT}+\mathrm{RT}$ & Excitus (etiology?) $9 \mathrm{~m}$ \\
\hline 13. & M 70 & $\begin{array}{l}\text { Gallbladder carcinoma + EHBD } \\
\text { invasion + distal bile duct } \\
\text { invasion (frosen +) } \\
\text { Adenocarcinoma - G2, SM+ }\end{array}$ & $\begin{array}{l}\text { Bil: } 2.65, \mathrm{Ca}-19.9: 48 \\
\text { Distal surgical margin tumor } \\
\quad \text { positivity }\end{array}$ & $\begin{array}{l}\text { Liver S4B + } 5 \text { resection + EHBDR } \\
+\mathrm{WP}+\mathrm{PE}(2019)+\mathrm{CT}+\mathrm{RT}\end{array}$ & $\begin{array}{l}\text { Stabile }+\mathrm{CT}+\mathrm{RT} \text { multiple } \\
\quad \text { lung metastasis }+ \\
\text { cholangitis, } \\
\text { excitus } 3 \mathrm{~m}\end{array}$ \\
\hline 14. & M 55 & $\begin{array}{l}\text { Klatskin tumor (type 4) } \\
\text { Adenocarcinoma - G3, SM+ }\end{array}$ & $\begin{array}{l}\text { Bil: 18.4, CA-19.9: } 400 \\
\text { Frosen; right and left hepatic } \\
\text { bile duct margins were } \\
\text { tumor positive }\end{array}$ & $\begin{array}{l}\text { Right hepatectomy + caudate lobe } \\
\text { resection + EHBDR + PE (2019) } \\
\text { CT + RT }\end{array}$ & Stabile, $9 \mathrm{~m}$ \\
\hline 15. & M 54 & $\begin{array}{l}\text { EHBD tumor } \\
\text { Adenocarcinoma - G2, SM+ }\end{array}$ & $\begin{array}{l}\text { Bil: } 24.75, \text { Ca19.9: } \mathrm{N} \\
\text { Proximal and distal surgical } \\
\text { margins tumor positivity }\end{array}$ & $\begin{array}{l}\text { EHBDR + PE + WP } \\
\text { (2nd Operation) } \\
\text { (2019) + CT + RT }\end{array}$ & Stabile, $6 \mathrm{~m}$ \\
\hline
\end{tabular}

$C O P D$ chronic obstructive pulmonary disease, $C T$ Chemothreapy, $G$ tumor grade, $E H B D R$ extrahepatic bile duct resection, $m$ month, $P T C$ percutan transhepatic cholangiography, $R T$ radiotherapy, $S M$ surgical margin, WP Whipple procedure

palliative resection stage $[17,18]$. In some cases where the negative surgical margin is provided, segmental bile duct resection is necessary. In such cases, a large number of segmental bile duct ends (the cut end) become free, and the drainage technique to be applied is crucial. Six of our cases were palliative; 5 of them had curative biliary tract resection, including segmental bile ducts. The patency of the anastomosis remained open in 13 of our patients. Percutaneous balloon dilatation performed in one patient. Hwang et al. reported that anastomosis patency was more effective than other drainage methods in PE series [4]. We think that there is the role of many bile duct opening up to a larger/wide channel, and also any pathological process first may affect any bile duct but does not interfere with the flow of bile from the other channels.

Since most of the patients undergoing resection and portoenterostomy are expected to develop recurrence or metastasis, it is recommended to administer capecitabine to patients as adjuvant chemotherapeutic agents, especially after the BilCap trial [19]. It is also applied in our patients.

The 5-year survival rate was reported as $11-45 \%$ in patients undergoing curative resection and $0-23 \%$ in patients with $\mathrm{R} 1$ resection in the literature [10]. Many studies are stating that there is no difference between surgery with negative surgical margin and positive surgical margin, and also, some studies state that palliative resection positively affects survival 


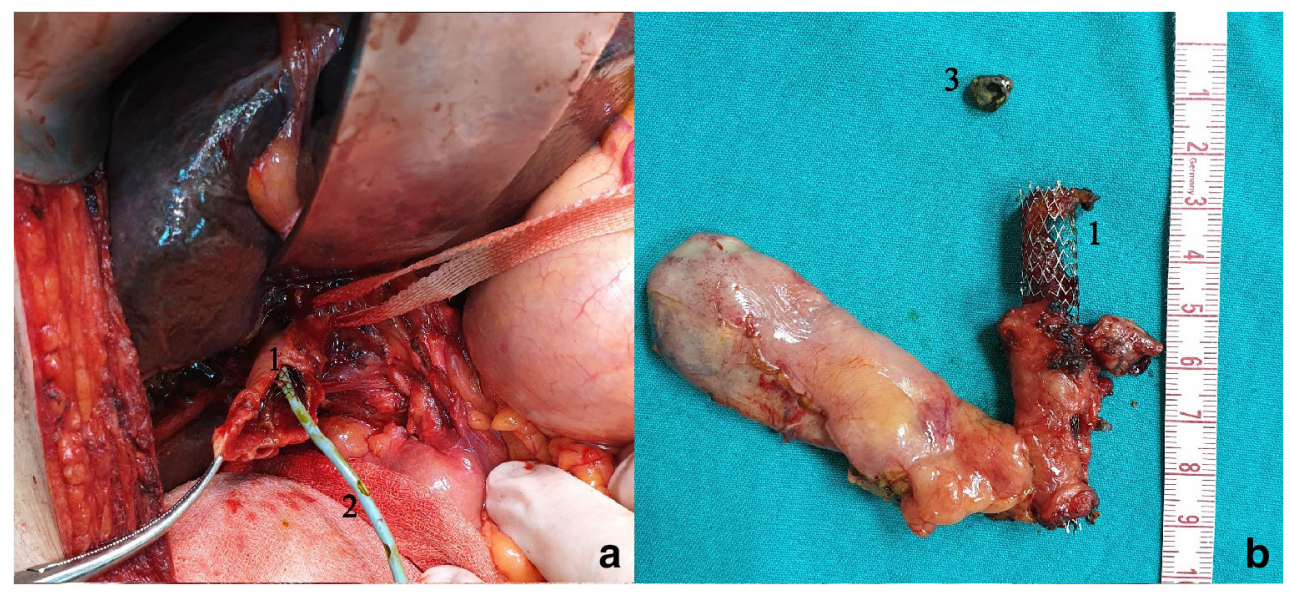

Fig. 4 Surgery (a) picture shows that the inner stent (2, blue) was placed with PTC due to the tumor ingrowth of the metal stent (1). Specimen (b) shows gallbladder and main bile duct and hepatolithiasis (3). (R, right hepatic bile ducts; L, left hepatic bile ducts)

$[8,18]$. The Mayo Clinic has reported promising results in 1 , 3 , and 5 -year survival $92 \%, 82 \%$, and $82 \%$, respectively, in the series of liver transplantation after neoadjuvant therapy in selected hilar cholangiocarcinoma cases. The 1,3, and 5-year survival rates for the standard surgery (biliary tract resection and hepatectomy) series of the same clinic were reported as $82 \%, 48 \%$, and $21 \%$, respectively. However, there is no consensus regarding the standard treatment of transplantation for hilar cholangiocarcinomas [10, 20]. In the hilar CCC series of 156 cases of Malik et al., 44 patients underwent hepatectomy. In the same series, mean survival was 50.3 months for resected patients and 9.8 months for those without resection. They reported that survival was longer in patients with extended left hepatectomy and en bloc resection of the caudate lobe. They also say that extended left hepatectomy is an independent risk factor for survival [21].

One of the most feared complications of hepaticojejunostomy is bile leakage (0.4-8\%) [9, 22, 23]. Infection, ischemia, edema, applied techniques, and anastomotic tension in the bile ducts that are dissected are the most important causes of bile fistula. The presence of a missed bile duct ends may also be a cause of persistent bile fistula. In this case, there are studies suggesting re-anastomosis or ethanol injections [24]. It may be an advantage if the missed bile ducts remain within the anastomosis area with the PE technique to be applied. In one of our cases, a biliary fistula was seen in the early postoperative period, which has a low flow of spontaneous healing in the first week. Some surgeons prefer interrupted sutures in the anterior wall and continuous sutures in the posterior wall, and also some surgeons prefer interrupted sutures for the whole anastomosis. In a large survey study in Germany, it has been reported that both techniques are equally preferable when performing hepaticojejunostomy, and there is no difference in complications [22]. We used an interrupted suture technique in all cases.

The development of stricture in the anastomotic line after hepaticojejunostomy $(12-25 \%)$ is a serious problem [23]. The tension in the anastomotic region, the suture material used, the ischemia due to aggressive dissection, and the fibrosis and adhesions in the course of the development of the biliary fistula may lead to a biliary stricture in the later period. In cases of stenosis developing in patients undergoing PE surgery due to biliary atresia, revision results are not good, and transplantation is recommended. The development of stricture in the hepaticojejunostomy line after liver transplantation is one of the most feared complications, and up to $40 \%$ prevalence series have been reported [25]. de Revuer et al. reported that they had to perform Roux-en-Y jejunal limb in almost all of the cases despite endoscopic and interventional treatments in patients with anastomotic stricture followed by biliary tract trauma [26]. Also, to increase the postoperative quality of life more effectively, they should be treated more aggressively in the early period instead of the duct-to-duct anastomosis. Revisions further disrupt the anatomy of the hilar region and increase the development of fibrosis [27]. PE appears to be less risky, especially in cases of anastomotic dehiscence and bile leakage [6]. In one of our cases, repeated endoscopic and percutaneous dilatations were made, and plastic and metal stents were placed to treat the stricture developed after hepaticojejunostomy. However, follow-up and management of the patient after metal stenting in the benign strictures of the biliary tract were difficult. Depending on the metal stent, dense fibrosis, mucosal/tumor ingrowth developed, and ultimately stent became dysfunctional. A plastic stent was placed through the metal stent in a percutaneous manner, but recurrent cholangitis attacks could not be prevented in this case. In this patient, the cut ends of the 4 and 6 segmental bile ducts were revealed with the extraction of adjacent bile ducts along with the ingrowth metal stent (Fig. 4). The stents that were placed with PTC were taken in the early postoperative 15 th day after MRCP or PTC cholangiography. However, series of stents placed into the bile duct up to 9-25 months have also been reported [5]. Mercado et al. reported that they performed $\mathrm{PE}$ in 26 patients for major bile duct trauma and placed transanastomotic stents in 9 patients for 9 months [28]. 
Due to the high bilirubin (mean $17.97 \mathrm{mg} / \mathrm{dL}$; range $6.17 \mathrm{mg} / \mathrm{dL}$ to $25+\mathrm{mg} / \mathrm{dL}$ ) values in all patients who underwent surgery due to the tumor, the ERCP stenting was administered in 4 patients and PTC stenting in 7 patients. The reason for this is that the patients usually come with jaundice and the process is prolonged due to diagnostic tests/procedures and pre-operative preparations. It is well known that bilirubin elevation and stentdependent cholangitis cause delayed treatment and increased morbidity. Comorbidities also play a significant role in the survival of patients. Our two patients died in postoperative second months due to pneumonia and COPD. Adjuvant radiotherapy and chemotherapy protocols have also been applied in our patients (Table 1).

Survival rates of the series with palliative resection have been reported to vary between 10 and 28 months. In contrast, in the series with biliary bypass or photodynamic therapy (PDT) in some cases, survival can change between 5.6 and 16 months $[8,21,29]$. Survival was reported between 1.4 and 8.7 months in patients with inoperable hilar cholangiocarcinoma who performed the endoscopic or percutaneous interventional procedure. In the same series, it is noted that there is no significant difference in terms of survival in series with surgical or interventional methods of palliative drainage [8, 29]. In brief, mean survival is 3 months in patients with inoperable hilar carcinoma and can be up to 4-10 months with palliative procedures [30]. The mean follow-up period of our series was 9.4 months (range 2 to 28 months).

\section{Conclusion}

Portoenterostomy instead of hepaticojejunostomy in small and multiple biliary radicles and bile duct cancers has been successfully performed in 15 patients of bile duct cancer and Klatskin tumor. In the presence of active inflammation, fibrosis, major bile duct trauma, and thin bile duct radicles, this method, which is described in detail, provides an excellent salvage surgical procedure with less morbidity.

\section{Authors' Contributions Concept - OND and TA; study design - OND and FHD; project writing and management-OND, AA, and FG; defining the study - ȘK, FHD, and FG; literature search - FG, AA, TA, and HB; actually performing the study, viz., OND, TA, and HB; experiments - OND; practical work - OND, ŞK, and FHD; operative work - OND, TA, $\mathrm{AA}$, and FG; data acquisition - OND, FHD, and ȘK; data analysis - OND, ȘK, and FHD; statistical inferences - OND; manuscript writing and repeated editing and reviewing of the manuscript - OND and FG.}

\section{Availability of Data and Material Yes.}

\section{Compliance with Ethical Standards}

Disclaimer This manuscript is original and neither published, accepted, or submitted for publication elsewhere.
Conflict of Interest The authors declare that they have no conflict of interest.

Ethics Approval Yes. As a routine procedure, written-signed informed consent form was obtained from all patients for treatment modalities and publication. İzmir Katip Celebi University, Atatürk Training, and Research Hospital, Human Research Ethics Committee approved study: 2019-GOKAE-1086.

Presentation This work has not been presented in any meeting.

\section{References}

1. Kasai M, Suzuki H, Ohashi E, Ohi R, Chiba T, Okamoto A (1978) Technique and results of operative management of biliary atresia. World J Surg 2:571-580

2. Cox CS, Hetz R Jr (2014) Operative treatment of biliary atresia. In: Mulholland MW, Albo D, Dalman RL, et al (eds) Operative techniques in surgery. Wolters Kluwer Health., EBSCO Publishing [eBook], Philadelphia, pp 939-948

3. Ha TY, Hwang S, Song GW, Jung DH (2015) Cluster hepaticojejunostomy is a useful technique enablingsecure reconstruction of severly damaged hilar bile ducts. J Gastrointest Surg 19:1537-1541

4. Hwang S, Ha TY, Song GW, Jung DH (2016) Cluster hepaticojejunostomy with radial spreading anchoring traction technique for secure reconstriction of widely opened hilar bile ducts. Korean J Hepatobiliary Pancreat Surg 20:66-70

5. Pickleman J, Marsan R, Borge M (2000) Portoenterostomy: an old treatment for a new disease. Arch Surg 135:811-817

6. Sharma A, Hammond JS, Psaltis E, Dunn WK, Lobo DN (2017) Portoenterostomy as a salvage procedure for major biliary complications following hepaticojejunostomy. J Gastrointest Surg 21: 1086-1092

7. Jarnagin WR, Fong Y, DeMatteo RP et al (2001) Staging, respectability and outcome in 225 patients with hilar cholangiocarcinoma. Ann Surg 234:507-517

8. Zhang BH, Cheng QB, XLou XJ et al (2006) Surgical therapy for hilar cholangiocarcinoma: analysis of 198 cases. Hepatobiliary Pancreat Dis Int 5:278-282

9. Hirano S, Tanaka E, Tsuchikawa T, Matsumoto J, Shichinohe T, Kato K (2012) Techniques of biliary reconstruction following bile duct resection [with video]. J Hepatobiliary Pancreat Sci 19:203209

10. Quinn LM, Dunne DFJ, Jones RP, Poston GJ, Malik HZ, Fenwick SW (2018) Optimal perioperative care in peri-hilar cholangiocarcinoma resection. Eur Surg 50:93-99

11. Lewis HL, Rahnemai-Azar AA, Dillhoff M, Schmidt CR, Pawlik TM (2017) Current management of perihilar cholangiocarcinoma and future perspectives. Chirurgia 112:193-207

12. Konstadoulakis MM, Roayaie S, Gomatos IP, et al (2008) Aggressive surgical resection for hilar cholangiocarcinoma: is it justified? Audit of a single center's experience. Am J Surg 196: $160-169$

13. Nimura Y, Kamiya J, Kondo S, et al (2000) Aggressive preoperative management and extended surgery for hilar cholangiocarcinoma: Nagoya experience. J Hepato-Biliary-Pancreat Surg 7:155-162

14. Moraca RJ, Lee FT, Ryan JA Jr, Traverso LW (2002) Long-term biliary function after reconstruction of major bile duct injuries with hepaticoduodenostomy or hepaticojejunostomy. Arch Surg 137: 889-894 
15. Nakanishi Y, Zen Y, Kawakami H, et al (2008) Extrahepatic bile duct carcinoma with extensive intraepithelial spread: a clinicopathological study of 21 cases. Mod Pathol 21:807-816

16. Matsuo K, Rocha FG, Ito K, et al (2012) The Blumgart preoperative staging system for hilar cholangiocarcinoma: analysis of resectability and outcomes in 380 patients. J Am Coll Surg 215:343-355

17. Rocha FG, Matsuo K, Blumgart LH, Jarnagin WR (2010) Hilar cholangiocarcinoma: the Memorial Sloan-Kettering Cancer Center experience. J Hepatobiliary Pancreat Sci 17:490-496

18. Öter V, Özer İ, Dalgıç T, Binarbașı C, Ulaș M, Bostancı EB (2019) Results of positive proximal margin after resection for hilar cholangiocarcinoma: an analysis of 42 cases. Turk J Gastroenterol 30: 88-94

19. Ghidini M, Pizzo C, Botticelli A, et al (2018) Biliary tract cancer: current challenges and future prospects. Cancer Manag Res 11: 379-388

20. Croome KP, Rosen CB, Heimbach JK, Nagorney DM (2015) Is liver transplantation appropriate for patients with potentially resectable de novo Hilar cholangiocarcinoma? J Am Coll Surg 221:130 139

21. Malik AK, Robinson SM, French JJ, et al (2019) Surgery for Hilar cholangiocarcinoma: the Newcastle upon Tyne liver unit experience. Eur Surg 51:197-205

22. Brunner M, Stockheim J, Krautz C, Raptis D, Kersting S, Weber GF, et al (2018) Continuous or interrupted suture technique for hepaticojejunostomy? A national survey. BMC Surg 18:84

23. Antolovic D, Koch M, Galindo L, et al (2007) Hepaticojejunostomy-analysis of risk factors for postoperative bile leaks and surgical complications. J Gastrointest Surg 11:555-561
24. Matsumoto T, Iwaki K, Hagino Y et al (2002) Ethanol injection therapy of an isolated bile duct associated with a biliary-cutaneous fistula. J Gastroenterol Hepatol 17:807-810

25. Tsui TY, Schlitt HJ, Obed A (2011) Prospective evaluation of biliary reconstruction with duct-to-duct continuous suture in adult live donor liver transplantation. Langenbeck's Arch Surg 396:209-215

26. de Reuver PR, Busch OR, Rauws EA, Lameris JS, van Gulik TM, Gouma DJ (2007) Long-term results of a primary end-to-end anastomosis in preoperative detected bile duct injury. J Gastrointest Surg 11:296-302

27. Bondoc AJ, Taylor JA, Alonso MH, et al (2012) The beneficial impact of revision of Kasai portoenterostomy for biliary atresia. An institutional study. Ann Surg 255:570-576

28. Mercado MA, Chan C, Salgado-Nesme N, Lopez-Rosales F (2008) Intrahepatic repair of bile duct injuries. A comparative study. J Gastrointest Surg 12:364-368

29. Li HM, Dou KF, Sun K, Gao ZQ, Li KZ, Fu YC (2003) Palliative surgery for hilar cholangiocarcinoma. Hepatobiliary Pancreat Dis Int 2:110-113

30. Bhardwaj N, Garcea G, Dennison AR, Maddern GJ (2015) The surgical management of Klatskin tumours: has anything changed in the last decade? World J Surg 39:2748-2756

Publisher's Note Springer Nature remains neutral with regard to jurisdictional claims in published maps and institutional affiliations. 